\section{Ethanol Enhances the Effectiveness of Ethephon on Anthocyanin Production in Cranberry Fruits in the Field}

\author{
Karim M. Farag', Jiwan P. Palta ${ }^{2}$, and Elden J. Stang ${ }^{3}$ \\ Department of Horticulture, University of Wisconsin, Madison, WI 53706
}

Additional index words. Vaccinium macrocarpon, fruit ripening, cuticle permeability, ethylene, fruit size, fruit color, Ethrel, ethephon transport

\begin{abstract}
The application of ethanol for enhancing effectiveness of ethephon under field conditions on cranberry (Vaccinium macrocarpon Ait.) fruit was tested during three seasons (1986 to 1988). The formulation containing ethephon plus the surfactant Tergitol $(0.3 \%$ or $0.5 \%$, v/v) and ethanol $(2.5 \%, 5 \%$, or $10 \%)$ consistently increased anthocyanin content in the fruit by $28 \%$ to $54 \%$ over the control. In general, fruit size was not affected by the ethephon treatment containing ethanol and Tergitol. The application of ethephon plus surfactant did not increase the anthocyanin content in the fruit. The presence of ethanol in the ethephon and surfactant mixture, however, consistently enhanced the fruit anthocyanin content by $21 \%$ to $40 \%$ as compared to ethephon plus surfactant. No adverse effect of various treatments on vine growth or appearance was noticed over the three seasons. Chemical name used: (2-chloroethyl) phosphonic acid (ethephon).
\end{abstract}

Chemical means to accelerate and increase anthocyanin content would increase profits for cranberry growers, since they are paid a bonus for pigmentation above a certain base. Ethephon has been used on cranberries in Wisconsin for increasing anthocyanin content. Its efficacy, however, has been inconsistent from season to season (Shawa, 1979). Cranberry fruit has a relatively thick cuticle that does not allow rapid diffusion of ethephon (Farag et al., 1985; Palta and Stang, 1983). The surface morphology and internal features of the cranberry cuticle do not lend themselves to thorough wetting or penetration of sprayed chemicals (Farag and Palta, 1987b). The berries have the potential to produce full and intense color if left on the vines for late harvest (Rigby et al., 1972; Shawa and Ingalsbe, 1968). Later harvest, however, requires frequent frost protection. Therefore, Wisconsin's growers usually harvest before the berries have reached their maximum anthocyanin content.

In our studies using enzymatically isolated fruit cuticles, we have demonstrated an enhanced penetration of ethephon in the presence of organic solvents (Farag et al., 1985). These results are expected considering the lipophilic nature of the cuticle (Kerler et al.,

Received for publication 26 Nov. 1991. Accepted for publication 4 Feb. 1992. This research was supported by the College of Agricultural and Life Sciences, Univ. of Wisconsin-Madison, and by the Wisconsin Cranberry Board. We would like to thank Dubay Cranberries, Junction City, Wis., and Whittlesey Cranberries. Wisconsin Rapids, Wis., for providing facilitiesfor field studies. The cost of publishing this paper was defrayed in part by the payment of page charges. Under postal regulations, this paper therefore must be hereby marked advertisement solely to indicate this fact. ${ }^{1}$ Research Associate.

${ }^{2}$ Professor (corresponding author). ${ }^{3}$ Professor.
1984). Lipid solubility of a penetrant is correlated with its penetration rate across a lipophilic membrane (Collander and Berlund, 1933; Kerler et al., 1984). In recent laboratory experiments, we have confirmed that the response of an intact fruit to ethephon is enhanced in the presence of ethanol (Farag, 1989). The studies reported here were conducted to evaluate the potential for enhancing fruit anthocyanin content by a mixture of ethephon and ethanol under field conditions.

A commercial cranberry ('Searles') bed established near Stevens Point, Wis., was used. Experiments were conducted over three growing seasons. Applications were made on 11, 14, and 12 Sept. for the 1986, 1987, and 1988 seasons, respectively. Ethephon dissolved in water $(\mathrm{pH} \approx 2.5)$ was applied (1000 $\mathrm{mg} \cdot$ liter $^{-1}$ ) using a hand sprayer (Spray Doc and 1988 seasons. $5 \%$, except mentioned; ethephon $1000 \mathrm{mg}^{- \text {liter }^{-1}}$.

y Mean separation in columns by LSD, $P=0.05$. model 207; Leigh Products, Saranac, Mich.) for the small-scale experiment $(1 \times 1 \mathrm{~m}$ for each plot) or by overhead boom sprayer for the large-scale experiment $(12 \times 50 \mathrm{~m}$ for each plot). Tergitol 15-S-9 was used as a nonionic surfactant $(0.3 \%$ or $0.5 \%, \mathrm{v} / \mathrm{v})$. In the small-scale experiment, each plot received $250 \mathrm{ml}$ of aqueous spray of one of the solutions, sufficient to provide wetting of leaves and fruit. In the large-scale experiment, the application rate was 1870 liters $\cdot \mathrm{ha}^{-1}$. Various combinations of ethephon and ethanol were tested. All the treatments were replicated four times in a completely randomized design. In the small-scale experiments, fruit samples were collected 2 weeks after spraying. Almost all of the fruit $(\approx 1500 \mathrm{~g})$ in the plot was hand-raked, put in plastic bags, and stored in a dark room overnight at $3 \pm 1 \mathrm{C}$. In 1986 and 1988 two subsamples (100 $\mathrm{g}$ each) and in the 1987 season four representative subsamples (100 $\mathrm{g}$ each) were taken from the berries collected from each plot. These samples were frozen at $-28 \mathrm{C}$ for later anthocyanin content analysis. In the large-scale experiment, fruit samples $(\approx 3 \mathrm{~kg}$ each) were collected 18 days after spraying. Four samples were randomly hand-raked from four sites in each plot. Two subsamples (100 g each) were taken from fruits collected from each site in the replication. The number of berries per $100 \mathrm{~g}$ was used as an indicator of fruit size. Anthocyanin content of fruit was determined by the procedure of Fuleki and Francis (1968). The data were tested by analysis of variance and comparisons of the treatment means were done using the least significant difference method.

The application of ethephon in the presence of the surfactant Tergitol did not increase anthocyanin production over three seasons (Table 1). The presence of ethanol ( $2.5 \%$ to $10 \%$ in different seasons), however, resulted in a consistent increase in anthocyanin content. This increase ranged from $21 \%$ to $40 \%$, as compared to ethephon plus Tergitol, and from $28 \%$ to $54 \%$, as com-

Table 1. The effect of various ethephon formulations on anthocyanin production and fruit size (expressed as the number of berries per $100 \mathrm{~g}$ fresh weight) of 'Searles' cranberry fruit in 1986, 1987,

\begin{tabular}{llcr}
\hline \hline $\begin{array}{l}\text { Season and } \\
\text { plot size }\end{array}$ & Treatments & $\begin{array}{c}\text { Anthocyanin contenty } \\
\text { (mg/100 g fresh wt) }\end{array}$ & $\begin{array}{c}\text { Fruit size } \\
\text { (no./100 g fresh wt) }\end{array}$ \\
\hline 1986 (small) & W & $19.5 \mathrm{a}$ & $90.6 \mathrm{a}$ \\
& $\mathrm{E}+\mathrm{T}(0.5 \%)$ & $20.6 \mathrm{a}$ & $96.1 \mathrm{~b}$ \\
& $\mathrm{E}+\mathrm{T}+\mathrm{EtOH}(10 \%)$ & $25.0 \mathrm{~b}$ & $90.0 \mathrm{a}$ \\
1987 (small) & $\mathrm{W}$ & $17.3 \mathrm{a}$ & $80.7 \mathrm{a}$ \\
& $\mathrm{E}+\mathrm{T}$ & $19.1 \mathrm{a}$ & $80.8 \mathrm{a}$ \\
& $\mathrm{T}+\mathrm{EtOH}$ & $19.3 \mathrm{a}$ & $80.8 \mathrm{a}$ \\
& $\mathrm{E}+\mathrm{T}+\mathrm{EtOH}$ & $26.7 \mathrm{~b}$ & $77.0 \mathrm{a}$ \\
1988 (small) & $\mathrm{W}$ & $20.7 \mathrm{a}$ & $100.9 \mathrm{a}$ \\
& $\mathrm{T}+\mathrm{T}$ & $21.9 \mathrm{a}$ & $99.1 \mathrm{a}$ \\
& $\mathrm{E}+\mathrm{T}+\mathrm{EtOH}$ & $23.3 \mathrm{a}$ & $102.3 \mathrm{a}$ \\
& $\mathrm{E}+\mathrm{T}+\mathrm{b}$ & $103.1 \mathrm{a}$ \\
1987 (large) & $\mathrm{W}$ & $28.2 \mathrm{a}$ & $86.7 \mathrm{ab}$ \\
& $\mathrm{E}+\mathrm{T}$ & $30.2 \mathrm{a}$ & $87.9 \mathrm{~b}$ \\
& $\mathrm{~T}+\mathrm{EtOH}(2.5 \%)$ & $27.9 \mathrm{a}$ & $82.3 \mathrm{a}$ \\
& $\mathrm{E}+\mathrm{T}+\mathrm{EtOH}(2.5 \%)$ & $37.8 \mathrm{~b}$ & $85.2 \mathrm{ab}$ \\
\hline
\end{tabular}

$\overline{{ }^{z} \mathrm{~W}}$, water; T, Tergitol; E, ethephon; EtOH, ethanol. Concentrations: Tergitol, $0.3 \%(\mathrm{v} / \mathrm{v})$ and ethanol 
pared to water. Application of Tergitol or ethanol alone had no effect on the anthocyanin development. The increase in anthocyanin content by ethephon spray containing ethanol varied over the three seasons. Variation in the ability of ethanol to enhance the ethephon effect on anthocyanin production could be accounted for by differences in weather conditions in the three seasons. Ethephon effectiveness has been reported to be higher in warm weather (Cooper et al., 1968). Among the three seasons, 1987 was the warmest. During this season we obtained the highest increase in anthocyanin content in the small plots by the application of ethephon plus ethanol plus Tergitol.

There was no influence on the fruit size by any of the treatments in the 1987 and 1988 small-scale experiments (Table 1). Furthermore, the spray solution containing ethephon, Tergitol, and ethanol did not influence the fruit size as compared to the control in the three seasons of study. These results confirm data on the lack of effect of ethephon on fruit size (Devlin and Demoranville, 1970; Eck, 1969; Rigby et al., 1972; Shawa and Ingalsbe, 1968). No adverse effects on the plants were noted. Reddening of the vines following ethephon application, before or during peak bloom, has been observed (Devlin and Demoranville, 1970). No such reddening was observed in our treated plants at the time of fruit harvest. Observations over three seasons showed no long-term adverse effect on the plants.

The possible explanation for the observed results could be enhanced diffusion of ethephon across the plant cuticle in the presence of ethanol. In vitro studies using enzymatically isolated cranberry fruit cuticles have demonstrated that the diffusion rate of ethephon can be significantly enhanced by ethanol (Farag et al., 1985). In addition, the presence of ethanol markedly increased the surface binding of ethephon to the cuticle outer surface (Farag, 1989) and increased the partitioning of ethephon into the cranberry fruit cuticle (Farag and Palta, 1987a). Ethanol therefore appears to enhance the effectiveness of ethephon by promoting its transport across the fruit cuticle. The results of our study demonstrate that the inclusion of ethanol appears to be a practical means to enhance anthocyanin in cranberry in the field.

\section{Literature Cited}

Collander, R and H. Barlund. 1933, Permeabilitatsstudien an Chara ceratophylla. Acta Bot. Fenn. 11:1-14.

Cooper, W.C., G.K. Rasmussen, B.J. Rogers, P.C. Reece, and W.H. Henry. 1968. Control of abscission in agricultural crops and its physiological basis. Plant Physiol. 43:1560-1576.

Devlin, R.M. and J.E. Demoranville. 1970. Influence of 2-chloroethylphosphonic acid on anthocyanin formation, size, and yield in Vaccinium macrocarpon cv. Early Black. Physiol. Plant. 23:1139-1143.

Eck, P. 1969. Effect of preharvest sprays of ethrel, alar, malathion on anthocyanin content of 'Early Black' cranberry (Vaccinium macrocarpon Ait). HortScience 4:224-226.
Farag, K.M. 1989. Enhancing effectiveness of ethephon under field conditions by modifying cuticular transport properties and by stimulating ethylene production in cranberry fruit. PhD Diss., Univ. of Wisconsin, Madison.

Farag, K.M. and J.P. Palta. 1987a. Use of ethanol to enhance penetration of ethrel across cranberry fruit cuticle: Influence on partition coefficient. Plant Physiol. 124:748. (Abstr.)

Farag, K.M. and J.P. Palta. 1987b. Surface morphology and cuticle development of 'Searles' cranberry leaves and fruits in relation to penetration of chemicals. HortScience 22:1080. (Abstr.)

Farag, K.M., J.P. Palta, and E.J. Stang. 1985. Chemical means of enhancement of ethrel transport across cranberry fruit cuticle. HortScience 20:276. (Abstr.)

Fuleki, T. and F.J. Francis. 1968. Quantitative methods for anthocyanins. I. Extraction and de- termination of total anthocyanin in cranberries. J. Food Sci. 33:72-77.

Kerler, F., M. Riederer, and J. Schonherr. 1984. Nonelectrolyte permeability in plant cuticle: A critical evaluation of experimental methods. Physiol. Plant. 62:599-602.

Palta, J.P. and E.J. Stang. 1983. Influence of cranberry fruit size on anthocyanin content, fruit anatomy and fruit density. HortScience 18:397. (Abstr.)

Rigby, B., M.N. Dana, and L.K. Binning. 1972. Ethephon sprays and cranberry fruit color. HortScience 7:82-83.

Shawa, A.Y. 1979. Effect of ethephon on color, abscission, and keeping quality of 'McFarlin' cranberry. HortScience 14:168-169.

Shawa, A.Y. and D.W. Ingalsbe. 1968. Anthocyanin enhancement in 'McFarlan' cranberries at optimum maturity. Proc. Amer. Soc. Hort. Sci. 93:289-292. 